
\title{
BReserch Square \\ CD86/Programmed Death-Ligand-1 as a Predictor Ratio for Response to Directly Acting Antiviral Therapy of Chronic Hepatitis in Egyptian Patients
}

\section{AM Attallah Attallah}

Biotechnology Research Center, New Damietta City, Damietta, Egypt

MM Omran Omran ( $\nabla$ drmmomran@science.helwan.edu.eg)

Faculty of Science, Helwan University

\section{A El Askary El Askary}

College of Applied Medical Sciences, Taif University

\section{Omran D Omran}

Cairo University

\section{Research Article}

Keywords: HCV, direct-acting antivirals, Predictors of response, Dendritic cells Co-stimulatory markers, Dendritic cells co-inhibitory marker, CD 86/ PDL-1 ratio

Posted Date: February 21st, 2022

DOI: https://doi.org/10.21203/rs.3.rs-1364775/v1

License: (9) This work is licensed under a Creative Commons Attribution 4.0 International License. Read Full License 


\section{Abstract}

\section{Objectives:}

Predictors of direct-acting antivirals response of HCV serve as assessment methods and help to treat doctors identify patients who are likely or unlikely to SVR.

\section{Methods:}

Egyptian chronic hepatitis $\mathrm{C}$ patients $(\mathrm{N}=300)$ were divided into 2 groups with 150 patients each. Group 1: received triple therapy (Sofosbuvir, Pegylated interferon, and ribavirin) for 12 weeks. Group 2: received dual therapy (Sofosbuvir and ribavirin) for 24 weeks. For all patients, routine blood markers, extracellular matrix markers, and dendritic cell markers were done. Hyaluronic acid, Collagen IV, Procollagen III peptide, laminin, platelet-derived growth factor and tissue inhibitor of metalloproteinase-1, were all performed using ELISA. Dendritic cells Co-stimulatory markers (CD40, CD83, and CD86), and co-inhibitory marker (PD-L1) were evaluated by real-time PCR.

\section{Results:}

SVR is associated with a decrease in the extracellular matrix markers and dendritic cell markers. AST/ALT $(p=0.003)$, Fibroscan ( $p=0.024)$, CDs co-stimulatory markers and PD-L1 $(p=0.05-p<0.0001)$ were differentiated between responders and non-responders. Using multivariate analysis exhibited that the decrease in PDL1 levels was significant $(p=0.012)$ and increase significant $(p=0.024)$ in CD86 associated with SVR. CD 86/ PDL-1 ratio had an AUC of 0.82 for prediction SVR.

\section{Conclusions:}

Baseline CD 86/ PDL-1 ratio was the only marker predicting SVR.

\section{Introduction}

Global, $\mathrm{CHC}$ with $\mathrm{HCV}$ is related to substantial morbidity and mortality [1]. About 170 million individuals are assessed to be diseased with HCV [2]. $\mathrm{CHC}$ is a main public health problem in Egypt, where it bears the uppermost occurrence rate in the world [3]. In Egypt, the HCV administration program aimed to reduce the HCV prevalence $(<2 \%)$ within ten years and $<1 \%$ by 2030 [4]. The treatment of HCV with DAA gives $90 \%$ SVR rates [5]. Second-generation DAAs (sofosbuvir, daclatasvir, and simeprevir) have been developed to provide more effective treatments for HCV than the first generation of DAAs (boceprevir and telaprevir) [6]. It is important to identify key predictors of response of HCV treatment and parameters that can be used to tailor treatment decisions [7]. Several studies evaluated viral and patient-related factors for pretreatment prediction of SVR rates for IFN [8]. Non-invasive markers that reflect the change in liver cells structure or functions liver and the SVR would be preferable [9]. In hepatic fibrosis, there is a difference between the production and analysis of the extracellular matrix. The extracellular matrix is composed of collagens, the non-collagenous glycoproteins (hyaluronic acid, laminin, and fibronectin). 
These markers are secreted by the liver cells and elevated in hepatic fibrosis [10-14]. DCS is the most powerful antigen-presenting cell and HCV infection altered many DCs functions. In HCV infection, alternations of DCs functions lead due to changes of major histocompatibility complex and costimulatory molecules. This led to weak T cell response and partially controls SVR [15]. This study aimed to evaluate baseline routine markers and extracellular matrix markers, DCs Co-stimulatory markers, and PD-L1 can be used as predictors of SVR.

\section{Materials And Methods}

\section{Study participants}

This study included 300 non-selected HCV-infected patients, consecutively treated from the National Hepatology and Tropical Medicine Research Institute, Kasr Al-Ainy, Faculty of Medicine, Cairo University. The $\mathrm{CHC}$ patients selected had to conform to the following inclusion criteria: detectable anti-HCV antibody and detectable serum HCV-RNA (COBAS Ampliprep/ COBAS TaqMan, Roche Diagnostics, Pleasanton, USA). Hepatic fibrosis staging was examined using FibroScan [16]. All patients were negative for hepatitis B surface antigen and HIV test. Other causes of hepatocellular injury were excluded. All patients were classified into two subgroups $(G)$ every 150 patients: Group 1: received triple therapy (Sofosbuvir, peg INF, and ribavirin) for 12 weeks. Group 2: received dual therapy (Sofosbuvir and ribavirin) for 24 weeks. SVR was defined as negative HCV-RNA post-triple and dual treatment. Fasting ten $\mathrm{ml}$ of blood samples were withdrawal from all patients and divided into three parts. The first part was treated with EDTA for assessment of HbA1C, platelet count, DCs Co-stimulatory markers, and PD-L1. The second part was treated with sodium citrate for prothrombin-INR. The third part left to coagulation and serum was separated for evaluation of baseline routine markers and extracellular matrix markers. The study was accepted by the local ethics committee and the Ethics guidelines of the 1975 Declaration of Helsinki were applied in this study. Informed consent was collected from each patient.

\section{Biochemical assays}

The liver profile was tested on an automated biochemistry analyzer (A15, Biosystem, Spain). Complete blood count was tested using a KX-21 Sysmex automated hematology analyzer (Sysmex Corporation, Kobe, Japan). Alpha-fetoprotein (AFP) was assessed by chemiluminescence, with Immulite (1000) AFP kit (Diagnostic Products Corporation; Los Angeles, CA, USA). Hyaluronic acid, Collagen IV, Procollagen III peptide, laminin, platelet-derived growth factor (PDGF), tissue inhibitor of metalloproteinase-1 (TIMP-1), and collagen IV (Shanghai Sunred Biological Technology Co., Ltd, Shanghai, China) were done according to the Attallah et al $[17,18]$. Fold changes of CD83, CD86, CD 40, and PD-L1 in peripheral blood mononuclear cells were determined according to [15].

\section{Statistical analysis}

Statistical analyses were performed by SPSS software v.22.0 (SPSS Inc., Chico go, IL) and Graph Pad Prism package; v.5.0 (Graph Pad Software, San Diego, CA). Qualitative data were evaluated using Chi- 
square $t$ for categorical variables and presented as numbers and percentages. Quantitative data were tested for normality distribution using the Kolmogorov-Smirnov test. Parametric data were tested using the ANOVA test or t-test and presented as mean \pm standard deviation. Non- parametric data were tested using the Mann-Whitney test and presented as median (Interquartile range). Correlations test was done using Pearson's test for - parametric data and spearman for non-parametric data. Univariate analyses were done for baseline routine markers and extracellular matrix markers, DCs Co-stimulatory markers, and PD-L1 then evaluated significant biomarkers using multivariate analyses. The independent discriminative values of significant variables for the SVR were assessed by receiver-operating characteristic (ROC) curves and stepwise linear discriminant analysis. In the second step, to calculate a ratio positive correlation parameter (CD 86) was put in the numerator and negative correlation parameters (PDL1) in the denominator [19]. Common indicators of CD 86- PDL1 ratio performances were presented.

\section{Results}

\section{Univariate analysis of laboratory markers}

After dual and triple treatment, 266 patients were responders and 27 non-responders, and 7 patients were missed and were excluded from further analysis. At the end of treatment, the SVR (138/146) was higher $(95 \%)$ in triple treatment patients than patients (128/147) who had received dual treatment (87\%) with significant differences $(p=0.02)$. Baseline routine biochemical markers and histological stages for responders and non-responders patients were presented in Table 1. The chief endpoint of this study was the developed ratio with discriminating responders and non-responders patients. To determine which markers could distinguish responders and non-responders patients, the routine blood markers, extracellular matrix markers, and dendritic cell markers of these two groups were examined. Except AST/ALT $(p=0.003)$. Baseline levels of extracellular matrix markers were higher in non-responders than responder patients (hyaluronic acid, collagen IV, PDGF-BB, Procollagen III peptide, laminin, TIMP-1, and PDGF-BB) without significant differences. There were significant decrease in FibroScan score $(p=0.024)$, all co-stimulatory markers and PDL1 $(p=0.05-p<0.0001)$ in responder patients in comparison to nonresponder patients; Table 2. 
Table 1

Clinical data of responder and non-responder after dual and triple HCV treatment.

\begin{tabular}{|c|c|c|c|}
\hline Variables & $\begin{array}{l}\text { Responders } \\
(\mathrm{N}=266)\end{array}$ & $\begin{array}{l}\text { Non-Responders } \\
(\mathrm{N}=27)\end{array}$ & $P$ value \\
\hline Age & $52.8 \pm 10$ & $51.7 \pm 11.1$ & 0.63 \\
\hline $\operatorname{Sex}(F / M)$ & $157 / 109$ & $15 / 12$ & 0.84 \\
\hline AST (U/L) & $30.0(23-54)$ & $34.0(21.0-42.0)$ & 0.417 \\
\hline ALT (U/L) & $27(25-35)$ & $33(23-42)$ & 0.62 \\
\hline AST/ALT ratio & $1.0(0.8-1.3)$ & $1.2(0.7-1.3$ & 0.003 \\
\hline Total bilirubin (mg/dl) & $0.87 \pm 0.37$ & $0.92 \pm 0.4$ & 0.55 \\
\hline Albumin (g/L) & $38.7 \pm 5.3$ & $38.2 \pm 5.1$ & 0.44 \\
\hline AFP (U/L) & $6.3(4-13)$ & $9.0(4-19)$ & 0.43 \\
\hline Platelet count $\left(10^{9} / \mathrm{L}\right)$ & $168 \pm 71$ & $152 \pm 55$ & 0.23 \\
\hline APRI & $1.1 \pm 0.61$ & $1.2 \pm 0.61$ & 0.32 \\
\hline Prothrombin-INR & $1.1 \pm 0.12$ & $1.2 \pm 0.12$ & 0.58 \\
\hline FBS (mg/dl) & $109 \pm 37.5$ & $112 \pm 31.6$ & 0.87 \\
\hline HbA1C (\%) & $6.0 \pm 1.0$ & $5.5 \pm 1.2$ & 0.162 \\
\hline F0 (No, \%) & $28(10.5 \%)$ & $0(0 \%)$ & \multirow[t]{8}{*}{0.17} \\
\hline F0-F1 (No, \%) & $6(2.3 \%)$ & $0(0 \%)$ & \\
\hline F1 (No, \%) & $21(7.9 \%)$ & $0(0 \%)$ & \\
\hline F1-F2 (No, \%) & $23(8.6 \%)$ & $3(11.1 \%)$ & \\
\hline F2 (No, \%) & $12(4.5 \%)$ & $0(0 \%)$ & \\
\hline F3 (No, \%) & $44(16.5 \%)$ & $7(25.9 \%)$ & \\
\hline F3-F4 (No, \%) & $19(7.1 \%)$ & $4(14.8 \%)$ & \\
\hline F4 (No, \%) & $113(42.5 \%)$ & $13(48.1 \%)$ & \\
\hline
\end{tabular}


Table 2

Baseline levels of dendritic cell markers and extracellular matrix markers associated with response for dual and triple HCV treatment.

\begin{tabular}{|llll|}
\hline Variables & Responders & Non-Responders & P value \\
\hline Fibroscan $(\mathrm{kPa})$ & $107.2(71.0-121.3)$ & $131.3(83.1-131.3)$ & 0.024 \\
\hline Hyaluronic acid $(\mathrm{ng} / \mathrm{mL})$ & $113.0(80.1-165.6)$ & $121(86.8-148.3)$ & 0.98 \\
\hline Procollagen III peptide $(\mathrm{ng} / \mathrm{mL})$ & $17.6(13.2-22.4)$ & $18.5(13.7-26.6)$ & 0.25 \\
\hline Collagen IV $(\mu \mathrm{g} / \mathrm{mL})$ & $7.3(5.9-9.9)$ & $8.0(5.9-13.9)$ & 0.35 \\
\hline Laminin $(\mathrm{ng} / \mathrm{mL})$ & $88.8(68.8-112.1)$ & $87.7(74.4-127.8)$ & 0.36 \\
\hline TIMP-1 $(\mathrm{ng} / \mathrm{mL})$ & $12.3(7.9-18.4)$ & $13.5(11.0-28.8)$ & 0.47 \\
\hline Platelet Derived Growth Factor -BB & $115.5(92.6-146.2)$ & $125.0(85.4-192.5)$ & 0.51 \\
\hline Programmed death-ligand 1 & $0.15(0.01-0.75)$ & $0.98(0.179-2.93)$ & $<0.0001$ \\
\hline CD40 & $0.89(0.29-2.1)$ & $0.43(0.023-1.24)$ & 0.04 \\
\hline CD83 & $0.67(0.12-1.4)$ & $0.28(0.03-0.80)$ & 0.017 \\
\hline CD86 & $0.76(0.14-2.1)$ & $0.08(0.015-0.73)$ & $<0.0001$ \\
\hline CD86/PDL-1 & $3.8(0.73-21.2)$ & $0.23(0.01-1.0)$ & $<0.0001$ \\
\hline
\end{tabular}

Evaluation of diagnostic performances of significant markers to predict SVR using the area under ROC

PDL-1 was the most effective marker among univariate significant markers (AST-ALT ratio, FibroScan score, DCs co-stimulatory markers, and PD-L1) with an AUC of 0.72 for SVR followed by of 0.71 for CD86, Table 3. Using multivariate analysis exhibited that the decrease in PDL1 levels was significant $(p=0.012)$ and increase significant $(p=0.024)$ in CD86 associated with the response of treatment; Fig. 1.

Table 3

Diagnostic performances of significant markers to predict SVR.

\begin{tabular}{|lllllllll|}
\hline Variables & AUC $(95 \% \mathrm{Cl})$ & P value & Cut-off & Sen & Spe & PPV & NPV & Accuracy \\
\hline Fibro scan & $0.63(0.53-0.74)$ & 0.03 & 13 & 52 & 59 & 93 & 11 & 53 \\
\hline AAR & $0.68(0.57-0.79)$ & 0.003 & 1.12 & 63 & 63 & 90 & 15 & 63 \\
\hline PDL1 & $0.72(0.61-0.83)$ & $<0.0001$ & 0.6 & 68 & 56 & 94 & 15 & 67 \\
\hline CD40 & $0.62(0.48-0.75)$ & 0.05 & 0.7 & 57 & 56 & 91 & 11 & 57 \\
\hline CD83 & $0.64(0.52-0.76)$ & 0.02 & 0.32 & 59 & 60 & 91 & 12 & 57 \\
\hline CD86 & $0.71(0.59-0.83)$ & $<0.0001$ & 0.1 & 74 & 52 & 91 & 20 & 74 \\
\hline CD86 / PDL1 & $0.82(0.75-0.94)$ & $<0.0001$ & 1.0 & 78 & 74 & 91 & 20 & 77 \\
\hline
\end{tabular}




\section{Development Of Cd 86/ Pdl-1 Ratio For Svr}

A ratio was developed named CD 86/ PDL-1 ratio $=(C D$ 86/PDL-1) using stepwise regression model. The level of ratio was higher in non-responder than responder with significant difference $(p<0.0001)$. The median (IQR) of CD 86/PDL-1 in female and male were (2.3 (0.63-12.9); (0.23-23) respectively without significant differences $(p=0.41)$. Using best cutoff $(\leq 1), C D 86 /$ PDL-1 ratio had a sensitivity of $78 \%$, specificity of $74 \%$ and efficiency of $77 \%$ for SVR; Fig. 1.

\section{86/ PDL-1 ratio for predict SVR in dual and triple treatment}

The levels of CD 86/ PDL-1 ratio in dual and triple treatment were presented in Fig. 2. The median levels of CD 86/ PDL-1 ratio were $4.1(0.74-24.9)$ in responder patients vs. $0.53(0.04-1.5)$ in non-responder in triple treatment. The median levels of CD 86/ PDL-1 ratio were 3.2 (0.65-18.0) in responder patients vs. 0.18 (0.01-0.68) in non-responder in dual treatment. Based on AUC, the CD 86/ PDL-1 ratio had the highest AUC for antiviral response in group 1, followed by the AUC of group 2 .

\section{Discussion}

Predictors of response help treating doctors identify patients who are possible or impossible to reach SVR. Thus, these measures decrease the hazard of side effects and fees [20]. In the present study, we examined several biomarkers that are related to liver fibrosis formation and response to treatment. These variables are clinical variables or laboratory markers. Levels of routine laboratory tests such as liver enzymes were increased without significant difference in non-responder patients in comparison to responder patients. Levels of AAR significantly differed between non-responder patients and responder patients. These results agreed with Nachnani et al [21] concluded that on univariate analysis, AST/ALT ratio, INR, and occurrence of fatty liver were associated with non-response of Pegylated-IFN-a2a plus Ribavirin. Patients with low HCV-RNA levels were associated with SVR compared with patients with high viral load [22]. Liver enzymes and synthetic functions tests had been described as indicators of prognostic markers for SVR. HOMA-IR index, insulin levels, viral load, glucose and liver histopathological, fatty liver score, and iron loading may have prognostic importance for SVR for Pegylated-IFN-a2a plus Ribavirin [23]. DAAs are directed toward HCV-specific proteins and were added to PEG-IFN/RBV, leading to higher SVR that significantly increase SVR when added to PEG-IFN [24]. A triple combination of DAAs increases SVR rates and shortage time of HCV treatment weeks [25]. The indicators of DAA non-response in Egyptian $\mathrm{CHC}$ patients were older age, advanced liver fibrosis, and low thrombocytopenia [26]. In the present study, routine blood markers, liver fibrosis index, extracellular matrix markers, and dendritic cell markers) were evaluated, while in other studies few markers were evaluated. Model-for-end liver disease and ALT reduction during therapy were found to be reliable in predicting markers of DAA sustainedvirological-response [27]. An SVR is related to a decrease in the fibrosis indicators, but the indicators do not reflect the disease activity during treatment. Baseline PIIINP was the only indicator for SVR [28]. Various studies have evaluated DC functions in chronic HCV. Our results exhibited that SVR patients exhibited higher levels of CD83, CD86, and CD40 and lower levels of PD-L1 in contrast to non-SVR 
patients. Non-responders had higher C-X-C motif chemokine-10 in responders and lower NK cells level, higher level of NKp30, and lower level of the NK subset CD56- CD16+ [29]. Our results agree with the finding described by [30] who indicated that HLA-DR, CD40, CD83, and CD86 were lower in CHC patients. In the present study, the multivariate analysis of several indicators presented that the independent markers to predict SVR were PDL1 and CD 86. The highest levels of CD 86 and lowest levels of PDL1 were found in responders. These markers could be used to exclude non-SVR to treatment with dual and triple treatment. There was a positive correlation with PDL1 levels and a negative correlation inversely related to PD-L1/CD86 ratio [31]. The effect of PD-L1 confuses the effect of co-stimulatory markers [32, 33]. Future researches directions may also focus on large number of patients, multicenter study other markers for SVR. In conclusion, the present study demonstrated that the CD 86-PDL-1 ratio can be used as a predictor ratio for response to triple and dual DAA treatment of $\mathrm{CHC}$ patients.

\section{Abbreviations}

AAR

ALT/AST ratio

AFP

Alpha-fetoprotein

ALT

alanine aminotransferase

AST, aspartate aminotransferase

AUC

Area under curve

$\mathrm{CHC}$

chronic hepatitis $\mathrm{C}$

DAAs, direct-acting antiviral agents

DCs

Dendritic cells

HCV

hepatitis $C$ virus

IQR

Interquartile range

LSM

liver stiffness measure

NK

nature killer

PDGF

platelet-derived growth

PD-L1

Programmed Cell Death Ligand 1 
PEG INF + RBV

pegylated interferon and ribavirin

Pegylated interferon

PEG- INF

RT-PCR

reverse transcriptase polymerase chain reaction

SVR

Sustaine dvirologic response

TE

transient elastography

TIMP-1

tissue inhibitor of metalloproteinase-1

\section{Declarations}

\section{Acknowledgements}

Not applicable.

\section{Authors' contributions}

AMA, DO and MMO have equal contributions in designing the study. DO, MMO, AE were investigators who performed all clinical, laboratory investigations and data development. AMA and MMO were writing original draft preparation. All authors read and approved the final manuscript.

\section{Funding}

The authors acknowledge the support of Taif University Researchers Supporting Project number (TURSP2020/82), Taif University, Taif, Saudi Arabia.

\section{Availability of data and materials}

The datasets generated and analysed during the current study are not publicly available due to limitations of ethical approval involving the patient data and anonymity but are available from the corresponding author on reasonable request.

\section{Ethics approval and consent to participate}

The study was conducted according to the guidelines of the Declaration of Helsinki and approved by Cairo University Research Ethics committee (N-65-2014). An informed written consent was obtained from all participants.

\section{Consent for publication}


Informed consent was obtained from all subjects involved in the study.

\section{Competing interests}

The authors declare no conflict of interest.

\section{References}

1. Puchades Renau L, Berenguer M. Introduction to hepatitis C virus infection: Overview and history of hepatitis C virus therapies. Hemodial Int 2018, 22:S8-S21.

2. Schinazi RF, Asselah T. From HCV to HBV cure. Liver Int 2017, 37:73-80.

3. Gomaa A, Allam N, Elsharkway A, El Kassas M, Waked I. Hepatitis C infection in Egypt: prevalence, impact and management strategies. Hepat med 2017, 9:17.

4. Omran D, Alboraie M, Zayed RA et al. Towards hepatitis $C$ virus elimination: Egyptian experience, achievements and limitations. World J Gastroenterol 2018, 24(38):4330.

5. Metwally AM, Elmosalami DM, Elhariri $\mathrm{H}$ et al. Accelerating Hepatitis $\mathrm{C}$ virus elimination in Egypt by 2030: A national survey of communication for behavioral development as a modelling study. PloS One 2021, 16(2):e0242257.

6. Khan HU, Khan S, Shah MA, Attaullah S, Malik MA. Pre-existing resistance associated polymorphisms to NS3 protease inhibitors in treatment naïve HCV positive Pakistani patients. Plos One 2020, 15(4):e0231480.

7. Kau A, Vermehren J, Sarrazin C. Treatment predictors of a sustained virologic response in hepatitis B and C. J Hepatol 2008, 49(4):634-651.

8. Wang Y-C, Yang S-S, Su C-W, Wang Y-J, Lee K-C, Huo T-I, Lin H-C, Huang Y-H. Predictors of response to pegylated interferon in chronic hepatitis B: a real-world hospital-based analysis. Sci Rep 2016, $6(1): 1-8$.

9. Karsdal MA, Krarup H, Sand J, Christensen P, Gerstoft J, Leeming D, Weis N, Schaffalitzky de Muckadell $\mathrm{O}$, Krag A. the efficacy of biomarkers in chronic fibroproliferative diseases-early diagnosis and prognosis, with liver fibrosis as an exemplar. Aliment Pharmacol Ther 2014, 40(3):233-249.

10. Arriazu E, Ruiz de Galarreta M, Cubero FJ et al. Extracellular matrix and liver disease. Antioxid Redox Signal 2014, 21(7):1078-1097.

11. Grønbæk H, Møller HJ, Saliba F et al. Improved prediction of mortality by combinations of inflammatory markers and standard clinical scores in patients with acute-on-chronic liver failure and acute decompensation. J Gastroenterol Hepatol 2021, 36(1):240-248.

12. Attallah AM, El-Far M, Malak CAA et al. A simple diagnostic index comprising epithelial membrane antigen and fibronectin for hepatocellular carcinoma. Ann Hepatol 2016, 14(6):869-880.

13. Attallah AM, El-Far M, Malak CAA et al. Fibro-check: a combination of direct and indirect markers for liver fibrosis staging in chronic hepatitis C patients. Ann Hepatol 2015, 14(2):225-233. 
14. Attallah AM, Abdallah SO, Attallah AA et al. Diagnostic value of fibronectin discriminant score for predicting liver fibrosis stages in chronic hepatitis C virus patients. Ann Hepatol 2013, 12(1):44-53.

15. Fouad H, El Raziky MS, Aziz RAA, Sabry D, Aziz GMA, Ewais M, Sayed AR. Dendritic cell costimulatory and co-inhibitory markers in chronic HCV: an Egyptian study. World J Gastroenterol 2013, 19(43):7711.

16. Sandrin L, Fourquet B, Hasquenoph J-M et al. Transient elastography: a new noninvasive method for assessment of hepatic fibrosis. Ultrasound Med Biol 2003, 29(12):1705-1713.

17. Attallah AM, Omran D, Omran MM et al. Extracellular matrix proteins substantiate IL-28B T allele effect on histological outcome of chronic hepatitis C. Ann Hepatol 2018, 17(4):569-576.

18. Attallah A, Albannan M, Omran M, Zayed R, Saif S, Farid A, Hassany M, Yosry A, Omran D. A panel of a mitogenic (PDGF), biochemical (albumin) and demographic (age) parameters for the non-invasive assessment of hepatic fibrosis. Br J Biomed Sci 2019, 76(3):105-110.

19. Attallah A, Omran M, Attallah A, Abdallah S, Farid K, Darwish H, El-Dosoky I, Shaker Y. HCC-ART score, a simple, highly sensitive and specific test for early diagnosis of hepatocellular carcinoma: a largescale, multicentre study. Br J Cancer 2013, 109(6):1657-1665.

20. Motawi TM, Rizk SM, Shaker OG, Mokhtar OZ. MicroRNAs as predictor markers for response to interferon treatment of chronic hepatitis C genotype-4 in Egyptian patients. PLoS One 2015, 10(3):e0121524.

21. Nachnani JS, Gidwani R, Sadeddin E, Clarkston WK, Fiorella R, Alba LM. Clinicopathological predictors to predict sustained viral response rates in patients with chronic hepatitis $\mathrm{C}$ infection. Indian J Gastroenterol 2007, 26(6):279-282.

22. Backus LI, Boothroyd DB, Phillips BR, Mole LA. Predictors of response of US veterans to treatment for the hepatitis C virus. Hepatology 2007, 46(1):37-47.

23. Ghenea $A E$, Ungureanu AM, Turculeanu $A$ et al. Predictors of early and sustained virological response of viral hepatitis C. Rom J Morphol Embryol 2020, 61(4):1185.

24. Kwo PY, Vinayek R. The therapeutic approaches for hepatitis $C$ virus: protease inhibitors and polymerase inhibitors. Gut Liver 2011, 5(4):406.

25. Hézode C. Direct-acting antiviral (DAA) actions in treatment-naïve patients. Clin Res Hepatol Gastroenterol 2011, 35:S52-S58.

26. Ahmed OA, Elsebaey MA, Fouad MHA et al. Outcomes and predictors of treatment response with sofosbuvir plus daclatasvir with or without ribavirin in Egyptian patients with genotype 4 hepatitis $C$ virus infection. Infect Drug Resist 2018, 11:441.

27. De Pace V, Morelli MC, Ravaioli M, Maggi F, Galli S, Vero V, Re MC, Cescon M, Pistello M. Efficacy, safety, and predictors of direct acting antivirals in hepatitis $C$ virus patients with heterogeneous liver diseases. New Microbiol 2019, 42:189-196.

28. Nøjgaard C, Johansen J, Krarup H, Holten-Andersen M, Møller A, Bendtsen F. Effect of antiviral therapy on markers of fibrogenesis in patients with chronic hepatitis C. Scand J Gastroenterol 2003, 38(6):659-665.

Page $11 / 14$ 
29. Childs K, Merritt E, Considine A, Sanchez-Fueyo A, Agarwal K, Martinez-Llordella M, Carey I: Immunological Predictors of Nonresponse to Directly Acting Antiviral Therapy in Patients With Chronic Hepatitis C and Decompensated Cirrhosis. Open forum infectious diseases 2017, 4(2):ofx067.

30. MacDonald A, Semper A, Libri N, Rosenberg W. Monocyte-derived dendritic cell function in chronic hepatitis $C$ is impaired at physiological numbers of dendritic cells. Clin Exp Immunol 2007, 148(3):494-500.

31. Shen T, Chen X, Chen Y, Xu Q, Lu F, Liu S. Increased PD-L1 expression and PD-L1/CD86 ratio on dendritic cells were associated with impaired dendritic cells function in HCV infection. J Med Virol 2010, 82(7):1152-1159.

32. Kakimi K. Immune-based Novel Therapies for Chronic Hepatitis C Virus Infection. Hum Cell 2003, 16(4):191-197.

33. Larsson M. The Dendritic Cell: The Immune System's Adjuvant-A Strategy To Develop a HCV Vaccine? Gastroenterology 2006, 130(2):603-606.

\section{Figures}



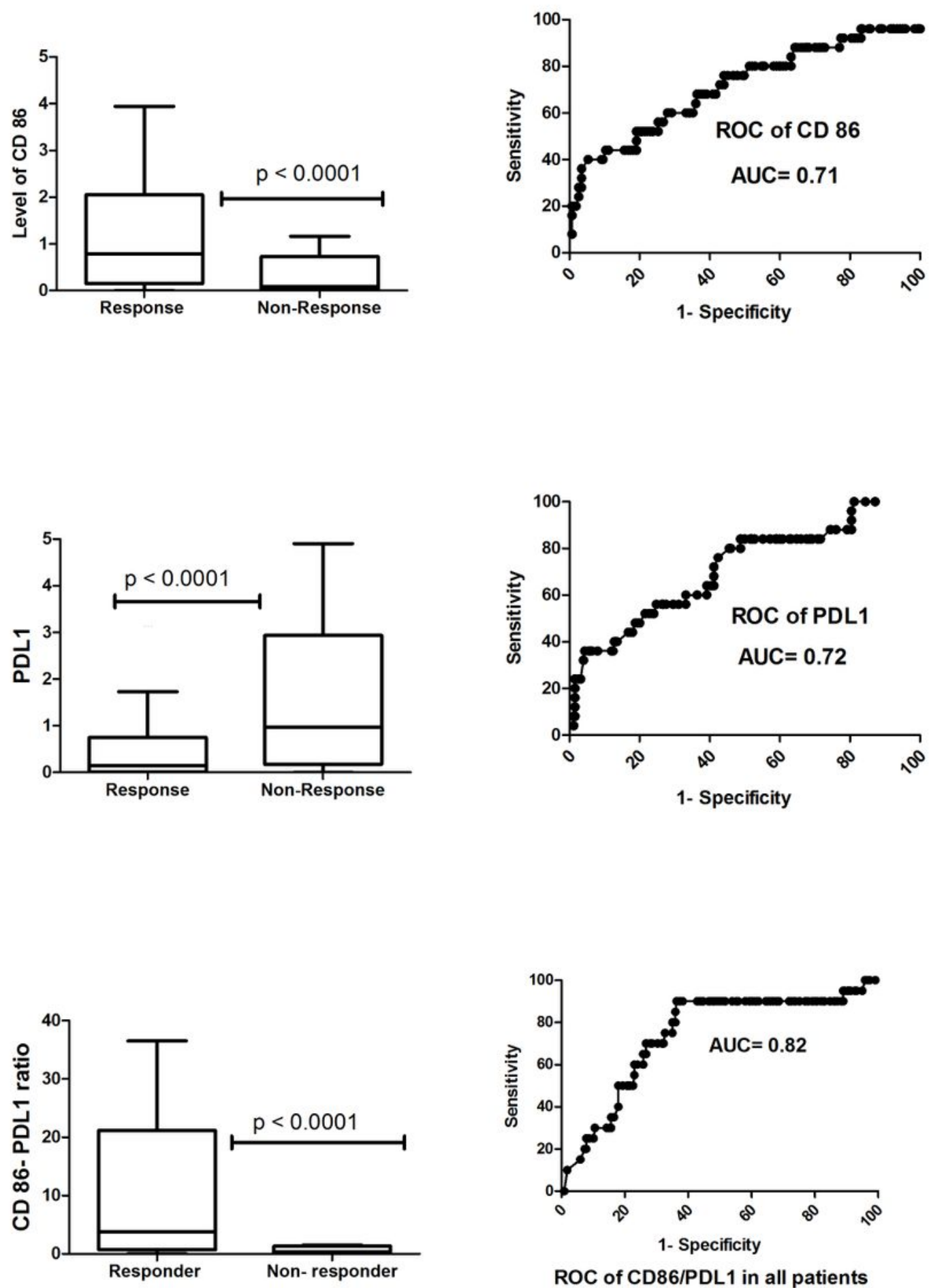

ROC of CD86/PDL1 in all patients

Figure 1

Caption not included with this version. 

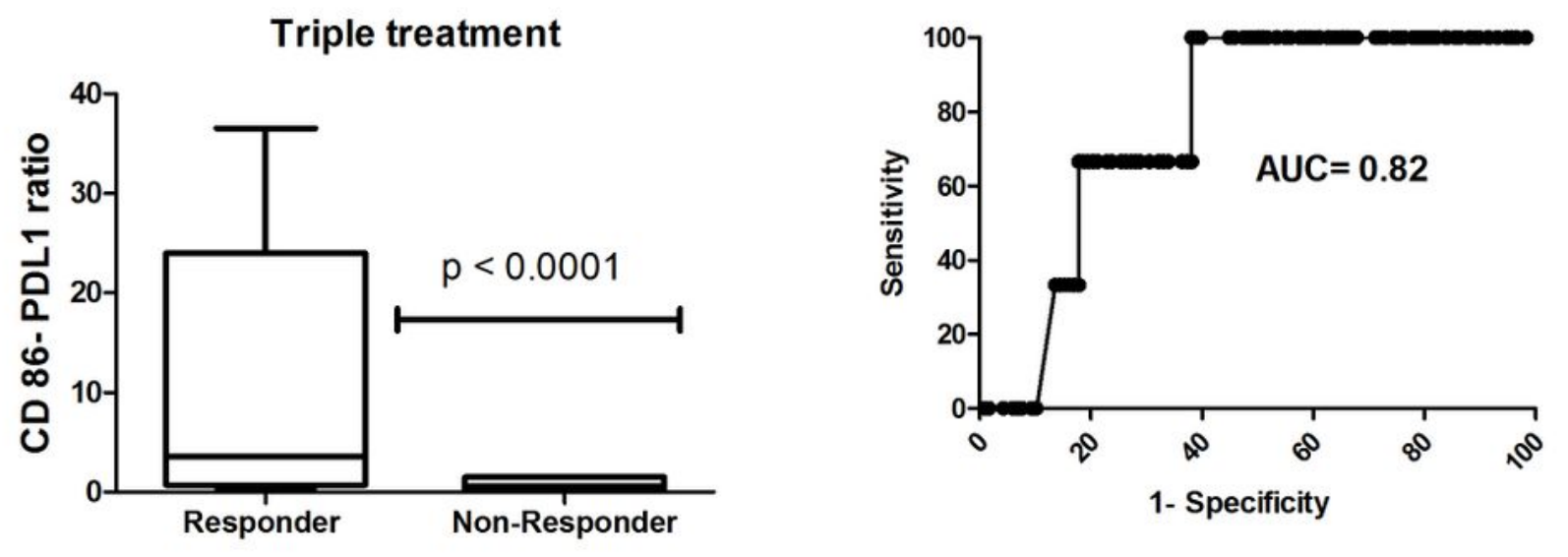

ROC of CD 86-PDL1 ratio for triple treatment
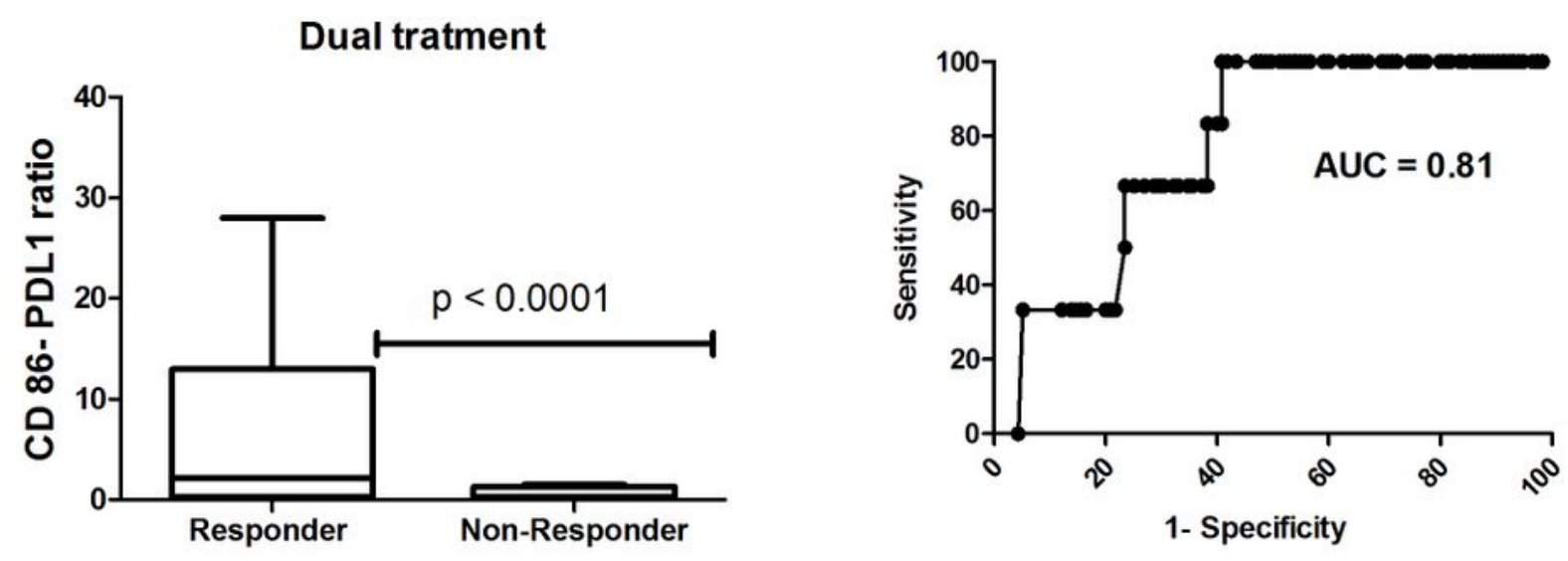

ROC of CD 86-PDL1 ratio for dual treatment

Figure 2

Caption not included with this version. 